OPEN ACCESS

International Journal of

Environmental Research and

Public Health

ISSN 1660-4601

www.mdpi.com/journal/ijerph

Article

\title{
Comparative In Vitro Toxicity Profile of Electronic and Tobacco Cigarettes, Smokeless Tobacco and Nicotine Replacement Therapy Products: E-Liquids, Extracts and Collected Aerosols
}

\author{
Manoj Misra *, Robert D. Leverette, Bethany T. Cooper, Melanee B. Bennett and Steven E. Brown \\ Lorillard Tobacco Company, A.W. Spears Research Center, 420 North English Street, Greensboro, \\ North Carolina 27405, USA; E-Mails: rleverette@lortobco.com (R.D.L.); \\ bethanycooper@lortobco.com (B.T.C.); mbennett@lortobco.com (M.B.B.); \\ sbrown@lortobco.com (S.E.B.)
}

* Author to whom correspondence should be addressed; E-Mail: mmisra@lortobco.com; Tel.: +1-336-335-6679; Fax: +1-336-335-6640.

External Editor: Konstantinos Farsalinos

Received: 1 August 2014; in revised form: 16 October 2014 / Accepted: 24 October 2014 / Published: 30 October 2014

\begin{abstract}
The use of electronic cigarettes (e-cigs) continues to increase worldwide in parallel with accumulating information on their potential toxicity and safety. In this study, an in vitro battery of established assays was used to examine the cytotoxicity, mutagenicity, genotoxicity and inflammatory responses of certain commercial e-cigs and compared to tobacco burning cigarettes, smokeless tobacco (SLT) products and a nicotine replacement therapy (NRT) product. The toxicity evaluation was performed on e-liquids and pad-collected aerosols of e-cigs, pad-collected smoke condensates of tobacco cigarettes and extracts of SLT and NRT products. In all assays, exposures with e-cig liquids and collected aerosols, at the doses tested, showed no significant activity when compared to tobacco burning cigarettes. Results for the e-cigs, with and without nicotine in two evaluated flavor variants, were very similar in all assays, indicating that the presence of nicotine and flavors, at the levels tested, did not induce any cytotoxic, genotoxic or inflammatory effects. The present findings indicate that neither the e-cig liquids and collected aerosols, nor the extracts of the SLT and NRT products produce any meaningful toxic effects in four widely-applied in vitro test systems, in which the conventional cigarette smoke preparations, at comparable exposures, are markedly cytotoxic and genotoxic.
\end{abstract}


Keywords: e-cigarette; snus; snuff; e-liquid; aerosol; cytotoxicity; mutagenicity; inflammation; condensate; in vitro

\section{Introduction}

The typical commercial electronic cigarette (e-cig) is comprised of three major components: a rechargeable or disposable battery, a heating element that generates an inhalable aerosol, and an associated switch or puff-activated circuitry. The circuitry serves to produce the aerosol only during the active puffing cycle, essentially eliminating sidestream emissions from the device during usage. The typical commercial e-cig also contains a liquid solution containing aerosol-forming excipients such as glycerol and/or propylene glycol, flavoring materials and, optionally, nicotine. This solution is usually delivered from a small reservoir by capillary wicking to the heating zone to affect the generation of an aerosol that superficially resembles cigarette smoke in appearance. A great variety of e-cig sizes, configurations, liquid formulations and designs are emerging on a continual basis in this rapidly-developing worldwide marketplace in response to users' evolving personal preferences.

As such, the popularity and sales volume of e-cigs continue to increase worldwide [1,2], and there is a need for a fuller scientific understanding of the potential benefits or risks that e-cigs may have, both to individual users as well as the general smoking and nonsmoking populations. A contemporary framework for assessing the relative risks and benefits to both individuals and populations must necessarily include the characterization of any potential toxicological hazard inherent to a product, and a consideration of those properties against those of other available alternative products. The individual risks to smokers and the harm to populations resulting from conventional cigarette smoking are very well understood and extensively documented [3]; however, the use of alternative products, such as electronic cigarettes, holds potential as an effective approach to advancing the public health amongst adult smokers in the near term [4-6].

It is well understood that tobacco cigarettes produce a multitude of harmful and toxic constituents that together induce deleterious health effects including chronic obstructive pulmonary disease (COPD), cardiovascular disease (CVD) and cancer [3]. Conversely, e-cigs do not burn tobacco and do not deliver harmful constituents in the numbers or in nearly the quantities that are found in the smoke of conventional tobacco cigarettes [7]. A recent review reporting on chemical, toxicological (mostly cytotoxicity studies on established cell lines) and clinical studies clearly indicates that e-cig liquids and aerosols contain far less and fewer chemicals, induce significantly less cytotoxicity or adverse effects, and result in considerably reduced cardiovascular and respiratory functional effects than are reported for tobacco cigarettes [8]. In prior investigations of aqueous extract of e-cig aerosols in mammalian fibroblast cells [9] and myocardial cells [10], some moderate cytotoxicity was observed for certain flavoring compounds found in the tested products. However, all such studies, to date, have reported the tested e-cig liquids and aerosols to be markedly less toxic than extracts prepared from the smoke of conventional cigarettes.

This study utilized an in vitro battery of established assays to examine the cytotoxicity (Neutral Red Uptake; NRU), mutagenicity (reverse bacterial mutagenicity test; Ames), genotoxicity (micronucleus 
formation; MN) and inflammatory effect (cytokine IL-8 release: IL-8) in cells exposed to preparations of various tobacco cigarettes, smokeless tobacco (SLT), nicotine replacement therapy (NRT) products, and commercial electronic cigarettes. Pre-incubation and in-media exposure methods were adopted for e-liquids, aqueous extracts of SLT, NRT products, and pad-collected aerosols from e-cigs as well as pad-collected smoke from tobacco cigarettes.

To date, no systematic toxicity studies have been reported that directly compared e-cig with SLT, NRT, and tobacco cigarettes. Therefore, the present comprehensive multi-endpoint study of a variety of tobacco and nicotine delivery products that have been previously assigned different positions on a risk continuum [11,12] was designed to address the following:

1. Toxicity of e-cig liquids;

2. Toxicity of SLT products;

3. Toxicity of a NRT lozenge product;

4. Toxicity of pad-collected particulate matter from freshly-generated smoke and aerosols from tobacco cigarettes and e-cigs, respectively.

\section{Materials and Methods}

\subsection{Chemicals and Methods}

All chemicals were purchased from Sigma-Aldrich (St. Louis, MO, USA) unless otherwise stated. Recommendations from Cooperation Centre for Scientific Research Relative to Tobacco (CORESTA) were followed for the selection of toxicological assays used in this study [13].

\subsection{Product Characterization}

Commercial blu e-cigs containing glycerol-based e-liquids, with and without nicotine and two market leader flavors (Classic Tobacco and Magnificent Menthol), were used in this study. For comparative purposes, tobacco burning cigarettes (Kentucky Reference 3R4F, 1R5F and Marlboro Gold), SLT products (Marlboro Snus, Copenhagen Snuff) and a NRT product (Nicorette Lozenge) were also tested. The products used in the study, their general specifications and the level of nicotine measured in test samples are detailed in Table 1.

\subsection{E-Liquid Extraction}

The e-liquids were extracted from the wicking material located inside the cartomizer for both rechargeable and disposable e-cigs under aseptic conditions. The mouth-end plug of e-cigs was removed and the polyester wicking material was removed with sterilized stainless steel forceps. The wet wicking material was then placed in a sterile $20 \mathrm{~mL}$ plastic syringe tipped with a sterile $0.45 \mu \mathrm{m}$ pore size syringe filter. The e-liquids from the wet wicking material were extracted by pushing the syringe plunger and collected in a sterilized test tube. About $1.0 \mathrm{~mL}$ of e-liquid was extracted from each e-cig. Subsequently, the e-liquids were diluted and delivered to the respective test systems. 
Table 1. Product Characterization.

\begin{tabular}{|c|c|c|c|c|c|}
\hline Product Class & Name/Description & Abbreviation & Lot \# & $\begin{array}{l}\text { Product Label } \\
\text { Nicotine }(\mathrm{mg}) \\
\end{array}$ & $\begin{array}{l}\text { Nicotine Measured in } \\
\text { Samples }(\mathrm{mg} / \mathrm{mL})\end{array}$ \\
\hline \multirow{3}{*}{$\begin{array}{c}\text { Tobacco } \\
\text { Cigarettes }\end{array}$} & Kentucky Reference & $3 \mathrm{R} 4 \mathrm{~F}$ & -- & 0.8 & $2.08 *$ \\
\hline & Cigarettes & $1 \mathrm{R} 5 \mathrm{~F}$ & -- & 0.2 & $1.27 \pm 0.10$ \\
\hline & Marlboro Gold, $72 \mathrm{~mm}$ & Marlboro Gold & V128Z33B4 & 0.68 & $1.96 \pm 0.08$ \\
\hline \multirow{5}{*}{$\begin{array}{l}\text { Electronic } \\
\text { Cigarettes } \\
\text { (e-cig) }\end{array}$} & Control e-cig & $\mathrm{N} / \mathrm{A}$ & -- & 0 & $0 \pm 0$ \\
\hline & $\begin{array}{l}\text { blu }^{\mathrm{TM}} \text { e-cigs Classic Tobacco } \\
\text { No Nicotine (Rechargeable) }\end{array}$ & blu CT-Ø & 0248 & 0 & $0 \pm 0$ \\
\hline & $\begin{array}{c}\text { blu }^{\mathrm{TM}} \text { e-cigs Classic Tobacco } \\
\text { High Nicotine (Cigalike) }\end{array}$ & blu CT-High & $270 / 404$ & 24.0 & $17.93 \pm 0.34$ \\
\hline & $\begin{array}{c}\text { blu' } \\
\text { Menthol No Nicotine } \\
\text { (Rechargeable) }\end{array}$ & blu MM-Ø & 237 & 0 & $0 \pm 0$ \\
\hline & $\begin{array}{c}\text { blu } \\
\text { Menthol High Nicotine } \\
\text { (Cigalike) }\end{array}$ & blu MM-High & 404 & 24.0 & $20.43 \pm 0.41$ \\
\hline Smokeless & Marlboro ${ }^{\circledR}$ Snus & $\mathrm{N} / \mathrm{A}$ & N335X0X50 & 15.7 & $0.42 \pm 0.14$ \\
\hline Tobacco (SLT) & Copenhagen ${ }^{\circledR}$ Snuff & $\mathrm{N} / \mathrm{A}$ & NEI31755H & 10.6 & $0.46 \pm 0.03$ \\
\hline $\begin{array}{c}\text { Nicotine } \\
\text { Replacement } \\
\text { Therapy (NRT) } \\
\end{array}$ & Nicorette ${ }^{\circledR}$ Lozenge & N/A & 13780 & 4.0 & $0.10 \pm 0.03$ \\
\hline
\end{tabular}

* Only one sample value.

\subsection{Pad-Collected Aerosols for Tobacco Cigarettes and E-Cigs}

All tobacco cigarettes were conditioned at $60 \%$ relative humidity at $24^{\circ} \mathrm{C}$ for at least $18 \mathrm{~h}$ prior to machine smoking. E-Cig batteries were charged immediately prior to use (rechargeable only). The e-liquid from the control e-cig contained a glycerol/water mixture, without flavors or nicotine, similar to the tested commercial products.

It has been suggested that realistic tobacco cigarette smoking, as well as the e-cig vaping profile, are more intense than the ISO machine smoking profile ( $35 \mathrm{~mL}$ puff volume, $2 \mathrm{~s}$ draw, $60 \mathrm{~s}$ puff interval). In the absence of a standardized vaping profile for e-cigs and our intention to compare e-cig toxicity with conventional cigarette toxicity, this study employed the Canadian Intense (CI) puffing conditions. Both tobacco and e-cigs were smoked on a VITROCELL ${ }^{\circledR}$ VC10 smoking robot (VITROCELL Systems, Waldkirch, Germany) under the CI puffing conditions: $55 \mathrm{~mL}$ puff volume, $2 \mathrm{~s}$ draw, $30 \mathrm{~s}$ puff interval, and $100 \%$ blocked air dilution in the case of tobacco cigarettes [14]. Wet Total Particulate Matter (WTPM) and e-cig aerosols were collected on Cambridge glass fiber filter pads, which capture in excess of $99 \%$ of cigarette smoke particulate matter. The filters were extracted into either dimethylsulfoxide (DMSO) for tobacco smoke or phosphate buffered saline (PBS) for e-cig aerosols, both to a final concentration of $40 \mathrm{mg} / \mathrm{mL}(\mathrm{w} / \mathrm{v})$ and stored at $-80{ }^{\circ} \mathrm{C}$ prior to analysis. 


\subsection{Aqueous Extract of Smokeless Tobacco (SLT) and Nicotine Replacement Therapy (NRT) Products}

Aqueous extracts from commercially available products obtained at retail outlets were prepared based on previously reported methods [15]. Products were suspended in PBS at $80 \mathrm{mg} / \mathrm{mL}$ (Dulbecco's PBS, \#14040, $+\mathrm{MgCl}_{2}+\mathrm{CaCl}_{2}$, Gibco, Grand Island, NY, USA). The suspension was incubated at $37{ }^{\circ} \mathrm{C}$ for $21-24 \mathrm{~h}$, shaking at $150 \mathrm{rpm}$ on a shaker incubator. The final suspension was then centrifuged at $12,000 \mathrm{~g}$ for $10 \mathrm{~min}$ to remove particulates, filter sterilized, aliquoted and stored at $-80{ }^{\circ} \mathrm{C}$ prior to analysis.

\subsection{Nicotine Measurement}

The level of nicotine in e-liquids and pad-collected smoke and aerosols was quantified using Gas Chromatography-Flame Ionization Detection (GC-FID) instrumentation with a six point calibration utilizing a nicotine standard concentration range [16]. The method precision "variability" was $0.3 \%-0.7 \%$, method accuracy was $97.4 \%-98.6 \%$, method LOD was $0.0524 \mathrm{mg} / \mathrm{g}$ and method LOQ was $0.1040 \mathrm{mg} / \mathrm{g}$.

\subsection{Cell Culture}

Human lung epithelial carcinoma cells A549 (ATCC\# CCL-185) were plated in 96-well plates in $200 \mu \mathrm{L}$ per well of complete medium (Ham's F-12K medium with $10 \%$ heat-inactivated fetal bovine serum (FBS), $2 \mathrm{mM} \mathrm{L-glutamine} \mathrm{and} 0.01 \mathrm{mg} / \mathrm{mL}$ gentamicin) at a seeding density of 75,000 cells $/ \mathrm{mL}$ and allowed to attach and grow overnight at $37{ }^{\circ} \mathrm{C}$ in an atmosphere of $5 \% \mathrm{CO}_{2}$ prior to exposures.

Chinese hamster ovary cells CHO-K1 (ATCC\# CCL-61) were seeded in 96-well plates at 2500 cells/well in complete growth medium (Ham's F-12K medium with $10 \%$ FBS and $0.01 \mathrm{mg} / \mathrm{mL}$ gentamicin) and allowed to attach and grow overnight $\left(37^{\circ} \mathrm{C}, 5 \% \mathrm{CO}_{2}\right)$ prior to exposures.

\subsection{Cell Treatment}

Cells were treated for approximately $24 \mathrm{~h}$ with increasing levels of e-liquids, aqueous extracts, WTPM or pad-collected e-cig aerosols in fresh complete cell media prior to any toxicological evaluations. The cellular treatment dose range used for e-cigs (e-liquids and pad-collected aerosols) was $0-20 \mathrm{mg} / \mathrm{mL}$ and for tobacco cigarettes $0-0.5 \mathrm{mg} / \mathrm{mL}$. The doses utilized for tobacco burning cigarette samples were based on dose range finding experiments that demonstrated high cytotoxicity occurring at or above $0.5 \mathrm{mg} / \mathrm{mL}$. Solubility limitations of e-liquids were observed at doses beyond 20 $\mathrm{mg} / \mathrm{mL}$; therefore, doses above $20 \mathrm{mg} / \mathrm{mL}$ were not utilized in this study. The cellular treatment dose range used for SLT and NRT samples was $0-27 \mathrm{mg} / \mathrm{mL}$, which incorporated the dose range previously utilized for smokeless tobacco products [15]. The toxicological responses were normalized with their respective vehicle controls, either DMSO for tobacco burning cigarettes or culture medium for all other samples.

\subsection{Cytotoxicity and IL-8 Assay}

Following cellular treatment with samples, a $200 \mu \mathrm{L}$ aliquot of the exposure medium was taken from each well and processed for IL-8 analysis, and the cells adhered to the wells were processed for the cytotoxicity assay. 
Cytotoxicity was measured in A549 cells by the NRU method [17,18]. In brief, the cell treatment medium was replaced with $1.5 \%(v / v)$ neutral red dye in fresh serum-free complete medium and incubated for $2.5 \mathrm{~h}$. The plates were then washed and the cell-incorporated neutral red dye was released and quantified by measuring absorbance at $540 \mathrm{~nm}$ on an Infinite M200 Pro spectrophotometer (TECAN, Morrisville, NC, USA). The $\mathrm{EC}_{50}$ for NRU $(\mathrm{mg} / \mathrm{mL})$ was calculated and compared using GraphPad Prism v. 5.02 (two tailed; for comparisons, statistical significance@ $p<0.05$ ).

The release of cytokine IL-8 was quantified [19] in cellular medium with an ELISA detection kit (Abazyme, Inc., MA, USA) by measuring absorbance at 450 on an Infinite M200 Pro spectrophotometer (TECAN). Results for the IL-8 release are reported as \% vehicle control and compared using GraphPad Prism v. 5.02 (two tailed; for comparisons, statistical significance @ $p<0.05$ ).

\subsection{Bacterial Mutagenesis Assay}

Ames reverse bacterial mutagenicity assays were conducted with the pre-incubation modification [20,21] in strains TA98 and TA100 with S9 activation. Aroclor-induced Sprague-Dawley rat liver S9 post-mitochondrial supernatant (Moltox, Inc., Boone, NC, USA), in $0.154 \mathrm{M} \mathrm{KCl,} \mathrm{was} \mathrm{used} \mathrm{for}$ the S9-cocktail (0.1 M phosphate buffer, $\mathrm{pH} 7.4 ; 8 \mathrm{mM} \mathrm{MgCl}_{2}, 33 \mathrm{mM} \mathrm{KCl}, 5 \mathrm{mM}$ glucose-6-phosphate (G-6-P), $4 \mathrm{mM}$ nicotinamide adenine diphosphate (NADP), 5\% ( $v / v) \mathrm{S} 9$-fraction).

The e-cig and SLT/NRT sample dose ranges utilized for the Ames reverse bacterial mutagenicity assay were $0-48 \mathrm{mg} / \mathrm{mL}$ and $0-3.2 \mathrm{mg} / \mathrm{mL}$, respectively, due to the sample solubility and sample volume limits of the Ames exposure system. This SLT/NRT dose range is similar to the dose range previously reported for smokeless tobacco product extracts tested in the Ames assay [15]. The control sample for e-cig liquids, e-cig pad-collected aerosols, SLTs and NRT was PBS and the control sample for WTPM from tobacco burning cigarettes was DMSO.

Exposures of Salmonella tester strains were performed as follows: $100 \mu \mathrm{L}$ of an overnight culture, $500 \mu \mathrm{L}$ of the $\mathrm{S} 9-$ mix, plus $25 \mu \mathrm{L}$ sample were combined in a sterile tube, capped and shaken at $250 \mathrm{rpm}$ for $20 \mathrm{~min}$ at $37{ }^{\circ} \mathrm{C}$ prior to the addition of $2.5 \mathrm{~mL}$ of histidine/biotin top agar and plated onto minimal glucose agar plates. Revertant colonies were counted after 48 hours of incubation at $37{ }^{\circ} \mathrm{C}$. All exposures were conducted in triplicate in a minimum of two independent experiments. All colonies were counted with an automated colony counter, Synbiosis ProtoCOL3 (Frederick, MD, USA). Activity reported as revertants per mg was calculated from the linear portion of the dose response curve and compared using GraphPad Prism v. 5.02 (slope analysis, two tailed; for comparisons, statistical significance@p<0.05).

\subsection{Micronucleus Assay}

The in vitro $\mathrm{MN}$ assay was performed in $\mathrm{CHO}-\mathrm{K} 1$ cells as previously described [22], utilizing the MN HitKit-K11-0001-1 (Thermo Fisher Scientific, Pittsburgh, PA, USA). Cells were exposed to samples in the absence of S9 for $20 \pm 2 \mathrm{~h}$ followed by treatment with the cytokinesis blocking agent, cytochalasin B. Cell viability was determined by the cytokinesis-block proliferation index (CBPI). MN frequency $(\% \mathrm{MN})$ was determined on a Cellomics ${ }^{\circledR}$ ArrayScan ${ }^{\circledR}$ VTi (Pittsburg, PA, USA) using the Micronucleus Bioapplication, V.4 software. Activity is reported as \% Control and compared using GraphPad Prism v. 5.02 (two tailed; for comparisons, statistical significance ${ }^{\circledR} p<0.05$ ). 


\section{Results and Discussion}

This in vitro comparative toxicological study was designed to evaluate e-liquids extracted from commercial e-cig products and pad-collected aerosols and smoke delivered by laboratory machine smoking of e-cigs and combustible tobacco cigarettes. Although several in vitro tests are routinely used and accepted by regulatory authorities, there are inherent limitations which affect the usefulness of the assays to predict toxicity potential of a substance in vivo, and especially in humans. Given that no single in vitro test can fully replicate in vivo test results, a battery of in vitro tests with a high concordance to in vivo models has the potential to establish a weight-of-evidence approach for evaluating the biological impact associated with e-cigs. In addition, the in vitro toxicological analysis of appropriate comparative product types further provides context for results that otherwise may be misleading or lack relevancy to the determination of biological activity.

A battery of toxicological endpoints that have been amply demonstrated to appropriately characterize the responses to cigarette smoke preparations was selected to provide points of reference in terms of the cytotoxicity, mutagenicity, genotoxicity, and inflammatory responses elicited by the tested e-cigs.

Genotoxicity (Ames and MN formation) testing is an important part of the hazard assessment of a chemical for regulatory purposes and has been demonstrated to have very high concordance with rodent carcinogenicity or in vivo genotoxicity when tested together [23]. Additionally, inadequate resolution of inflammation and uncontrolled inflammatory reactions can evoke a state of chronic inflammation, which is a common etiologic factor for various human respiratory lesions, including cancer [24,25].

A list of all products evaluated in this study is detailed in Table 1. This study utilized the CI smoking profile to smoke both e-cigs as well as tobacco cigarettes. As a basis for comparative analysis, this study evaluated the toxicological impact of traditional tobacco products, commercial Marlboro Gold and two Kentucky reference cigarettes, four blu e-cigs, Copenhagen Snuff, Marlboro Snus, and Nicorette Lozenge. In addition to comparing products in different classes (tobacco cigarette, e-cig, SLT and NRT), the toxicological impact of nicotine using e-cigs with and without nicotine was also investigated.

\subsection{E-Liquids, Smokeless Tobaccos (SLTs) and Nicotine Replacement Therapy (NRT): Cytotoxicity}

The toxicological response of e-liquids and aqueous extracts of SLT and NRT products was evaluated in A549 cells and is shown in Figures 1 A-E. No cytotoxicity was observed for any of the e-liquids, as well as for all SLT and NRT products tested up to their respective highest sample doses (Figure 1A).

Similarly, Bahl et al. reported little or no cytotoxicity for most of the 35 commercial refill liquids for e-cigs previously tested in human lung fibroblast cells [26]. This study utilized two blu e-cig market leading flavors, classic tobacco and magnificent menthol. To compare the dose levels, the maximum e-liquid dose utilized by Bahl et al. [26] was $12.6 \mathrm{mg} / \mathrm{mL}$, equivalent to the highest dose of $1 \%(v / v)$, assuming a $100 \mu \mathrm{L}$ MTT assay volume and an e-liquid density of about $1.22 \mathrm{~g} / \mathrm{mL}$. Additionally, Bahl et al. [26] also reported toxicity to adjacent wells at 10\% ( $v / v)$ e-liquid dilutions, equivalent to approximately $126 \mathrm{mg} / \mathrm{mL}$; however, the present study did not reveal any vapor toxicity 
from e-liquids at doses as high as $27 \mathrm{mg} / \mathrm{mL}$ to adjacent wells. The observed cytotoxicity in adjacent wells [26] may be a result of higher e-liquid concentrations used by Bahl et al. or the volatility of specific e-liquid ingredients or flavors released while incubating at $37{ }^{\circ} \mathrm{C}$, or the possibility of differential susceptibility of the lung fibroblasts used by Bahl et al. and the A549 cells used in this study.

Figure 1. In vitro activity of e-cig liquids, smokeless tobacco and lozenge aqueous extracts in NRU (A), Ames (B), MN (C and D) and IL-8 (E). NRU, MN and IL-8 data reported as $\%$ vehicle control, PBS in the case of e-liquids, SLT and NRT aqueous extracts. Data points in each plot represent the mean values \pm SD from a minimum of two (2) independent experiments. MN cell viability (D) shown to verify lack of $\mathrm{MN}$ induction is not due to

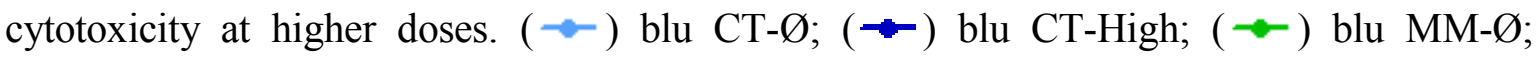
$(-\bullet)$ blu MM-High; $(-\bullet)$ Marlboro Snus; $(--)$ Copenhagen Snuff; $(-\bullet)$ Nicorette Lozenge; $(\bullet-)$ Control e-cig.

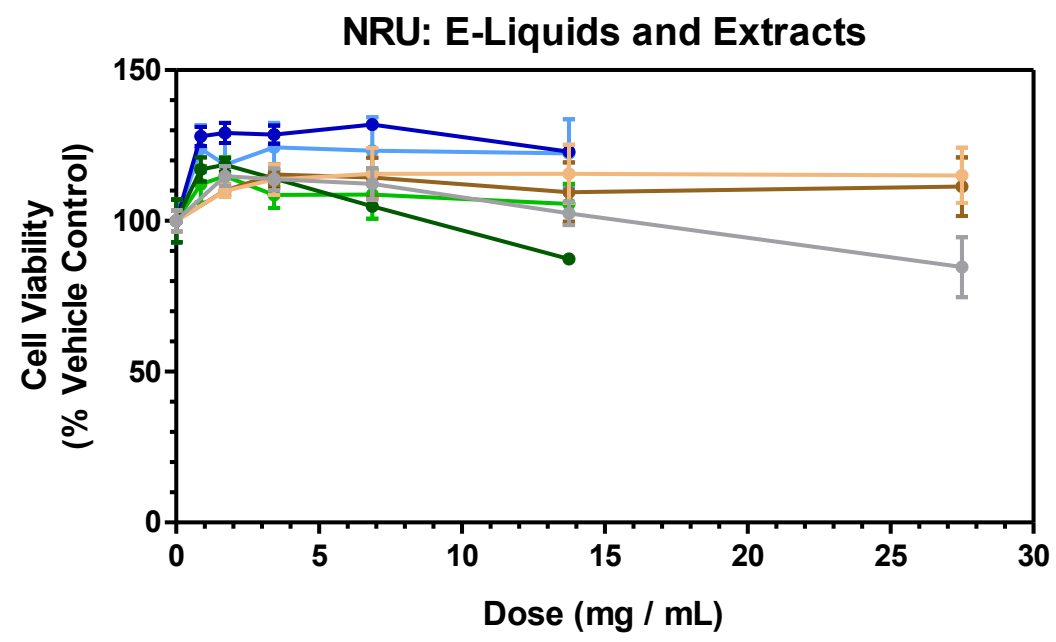

(A)

Ames: E-Liquids and Extracts

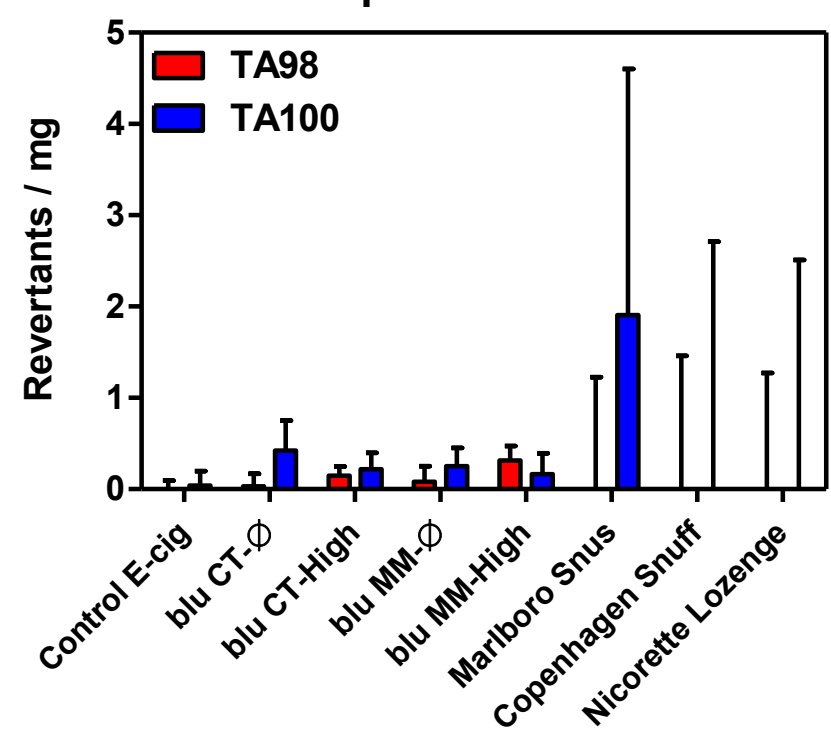

(B) 
Figure 1. Cont.

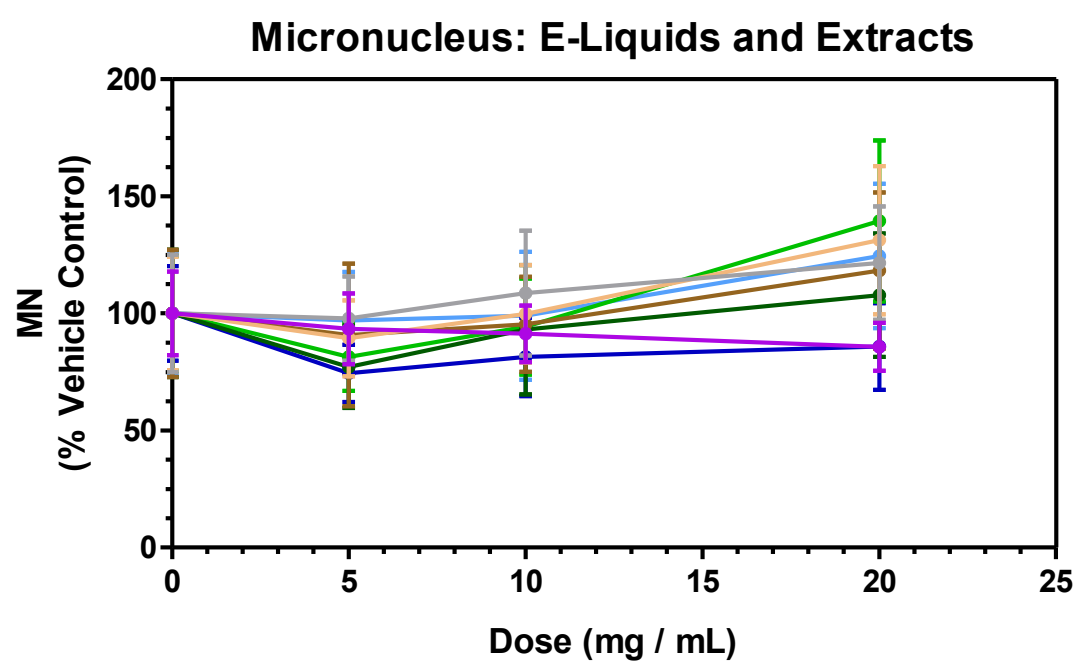

(C)

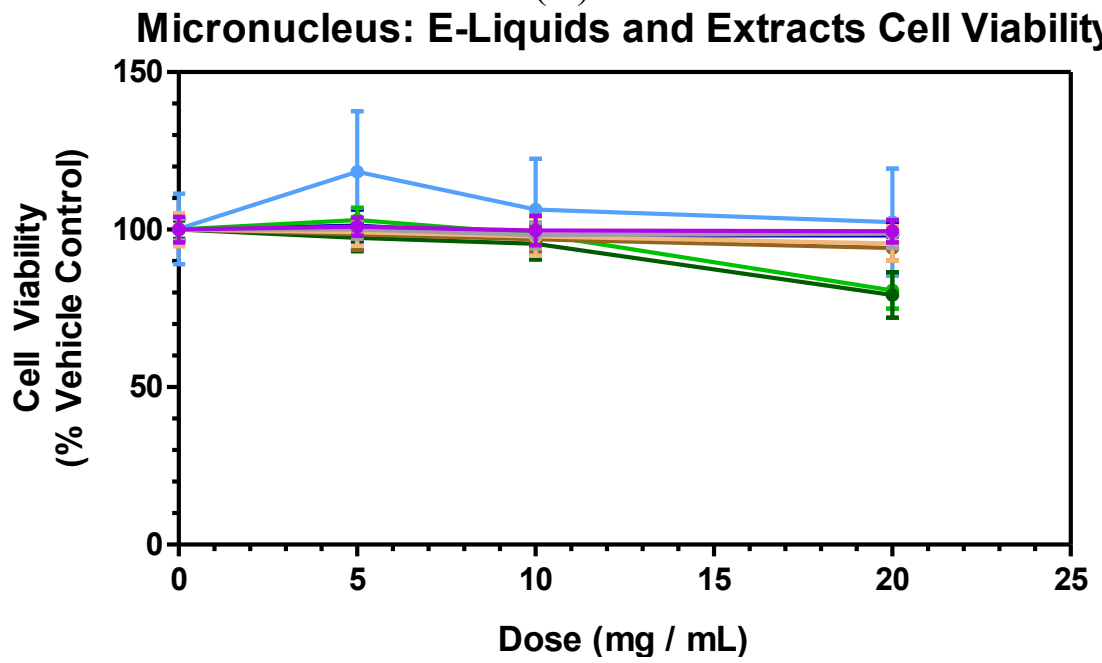

(D)

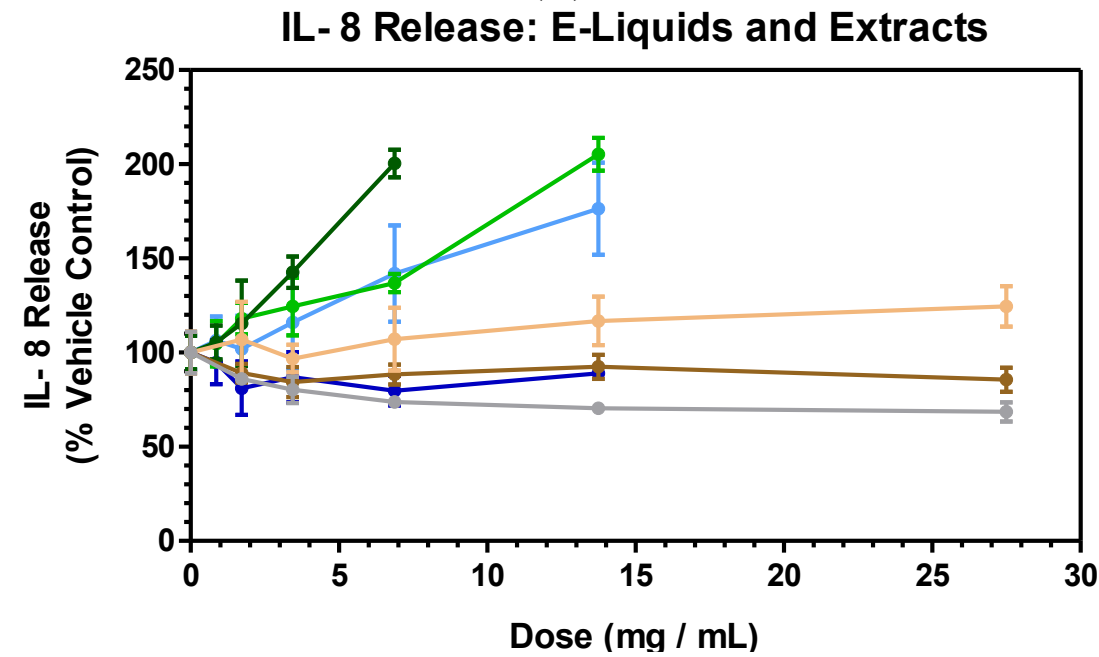

(E)

At the lower doses of e-liquids utilized in this study, an increase in cell viability was observed (Figure 1A) which was also evident with cells treated with lower doses of pure nicotine (Figure 2A). This increase in cellular viability was primarily associated with higher cellular proliferation and 
cellular protection mediated by the low level of nicotine exposure [27]. Therefore, there may be an association between the lower nicotine present in e-cig liquids and increased cellular viability, thus cellular protection.

Figure 2. Effects of L-nicotine on cytotoxicity (A) NRU and inflammation (B) IL-8 in A549 cells. Data points in each plot represent the mean values \pm SD from a minimum of two (2) independent experiments.

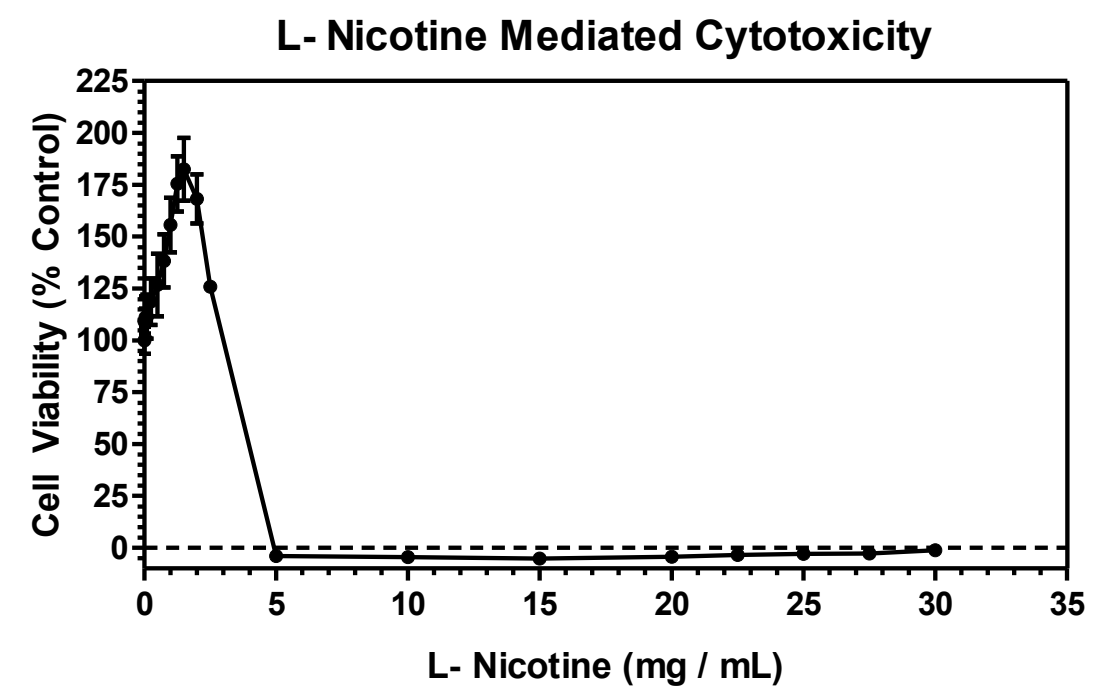

(A)

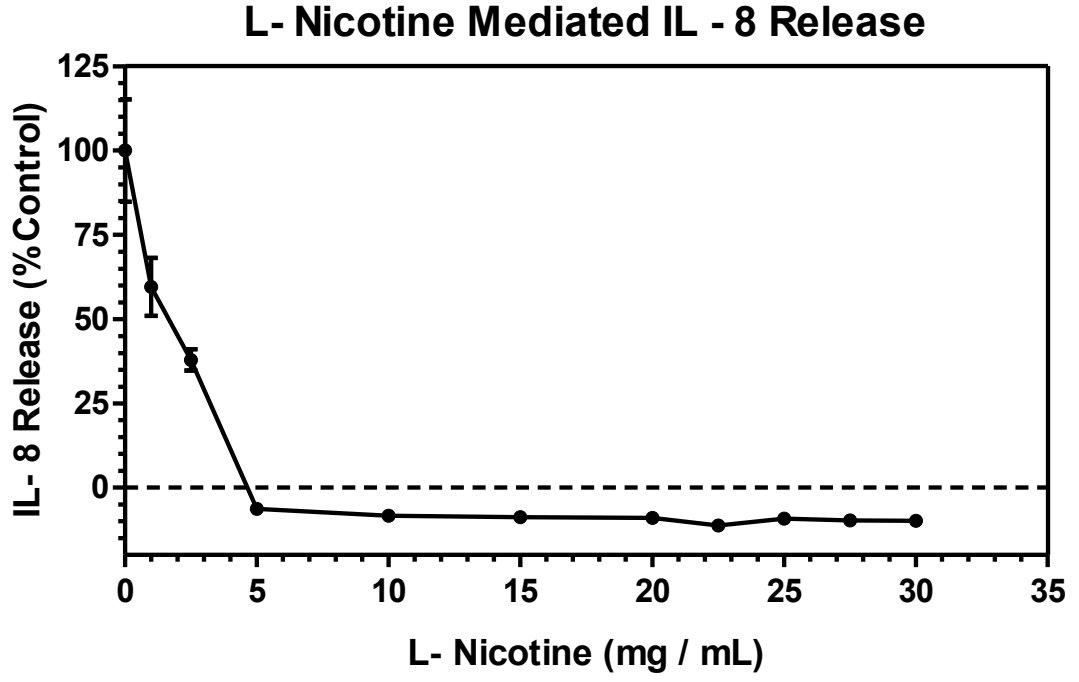

(B)

\subsection{E-Liquids, Smokeless Tobaccos (SLTS) and Nicotine Replacement Therapy (NRT): Mutagenicity}

The Ames test, also known as the bacterial reverse mutation assay, is widely used for the determination of a compound's ability to induce mutations and has been shown to have a high predictive value with rodent carcinogenicity tests [28].

The activity of e-liquids, SLT and NRT extracts in the Ames assay is shown in Figure 1B. The control e-cig sample containing water/glycerol and the PBS control sample (SLT and NRT) did not induce any revertants above baseline and were within the variability range of this assay. No significant induction in the activity over respective controls was observed for all e-liquids and extracts (Figure 1B). The level of 
e-liquids as high as 15-fold higher than SLTs and NRT extracts did not induce any activity. No evidence of cytotoxicity, as determined by the background bacterial lawn, was observed for all e-liquid, SLT and NRT samples at all doses tested.

\subsection{E-Liquids, Smokeless Tobaccos (SLTS) and Nicotine Replacement Therapy (NRT): Genotoxicity}

The results of in vitro $\mathrm{MN}$ formation assay are shown in Figure 1C,D). The MN assay conducted in CHO-K1 cells, identifies clastogenic and aneugenic chemicals which essentially cause a DNA-damaging event that leads to the disruption or breakage of chromosomes and ultimately results in sections of the chromosome being deleted, added, or rearranged upon cell division (mitosis) [29].

A sample dose range which does not produce cytotoxicity of more than $55 \pm 5 \%$ (compared to control) was utilized in the MN formation assay [24]. The control e-cig, e-liquids, SLT and NRT extracts did not induce any significant cytotoxicity at all dose levels tested since cell-viability remained around $100 \%$ of control at all concentrations (Figure 1D). No significant induction in the MN formation over respective controls was observed for all e-liquids and SLT and NRT extracts (Figure 1C).

\subsection{E-Liquids, Smokeless Tobaccos (SLTs) and Nicotine Replacement Therapy (NRT): Inflammation}

Airway epithelial cells are the first line of defense in the airways to respond to any external stimuli and secrete specific chemo-attractants and pro-inflammatory cytokines, for example IL-8, monocyte chemotactic protein-1, and IL-1B, in order to activate the secondary response for neutrophils and macrophage infiltration [30,31]. Instead of measuring downstream acute or chronic phase inflammation specific cytokines, this study measured an upstream pro-inflammatory cytokine, IL-8.

The effects of $24 \mathrm{~h}$ exposures of e-liquids and SLT and NRT extracts on IL-8 release in A549 cells are shown in Figure 1E. The control samples for e-cig, SLTs and NRT did not induce any significant IL-8 release. No significant IL-8 release was observed for most of the products, with the exception of the blu MM- $\varnothing$, blu MM-High and blu CT- $\varnothing$ treatments which resulted in higher IL-8 release only at extremely high doses of $6.9-13.8 \mathrm{mg} / \mathrm{mL}$. When compared to the IL-8 release induced by conventional cigarette samples (Figure 3E), any significant IL-8 release as a result of the blu MM e-liquid treatments occurred at doses approximately 42-fold higher than the conventional tobacco cigarettes. It has been suggested that the toxicity of e-liquids may change when the same e-liquids are heated to produce the inhaled aerosol [26]. The evaluation of e-cig aerosol toxicity is essential since the intended use of e-cigarettes is through aerosol inhalation. Additionally, it is proposed that different e-liquid formulation ingredients may evaporate differently, leading to changes in concentrations in the generated aerosols as well as the possibility that components may undergo modification when subjected to the heat used to generate the aerosol; therefore, the final composition of the aerosol may be different when compared to the e-liquid [9]. In the light of that, the purpose of the study was to also characterize the aerosol toxicity as delivered by heating the e-liquid. 
Figure 3. In vitro activity of pad-collected WTPM from tobacco cigarettes and pad-collected e-cig aerosols in NRU (A), Ames (B), MN (C and D), and IL-8 (E). NRU, MN and IL-8 data is reported as \% vehicle control; PBS in the case of e-cigarette pad-collected aerosols, DMSO for tobacco-burning cigarette pad-collected WTPM. Control e-cig exposures in NRU and IL-8 were at the highest deliverable dose, resulting in no observable cytotoxicity or IL-8 release above background levels (data not shown). Data points in each plot represent the mean values \pm SD from a minimum of two (2) independent experiments. MN cell viability (D) shown to verify lack of MN induction is not due to cytotoxicity at the higher doses.

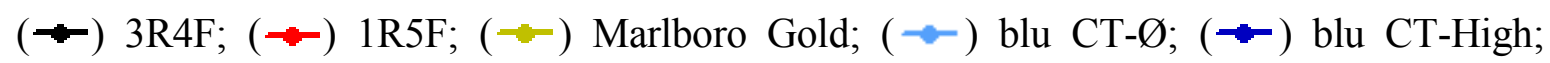
$(-\bullet)$ blu MM-Ø; (-๑) blu MM-High; $(-\bullet)$ Control e-cig.

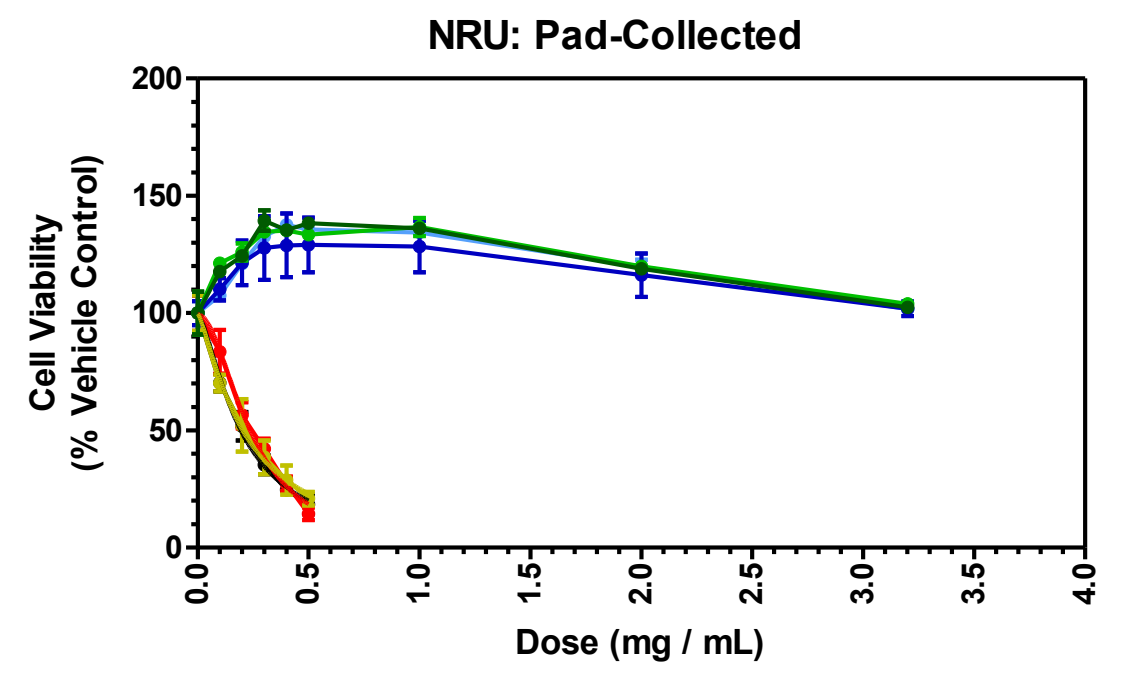

(A)

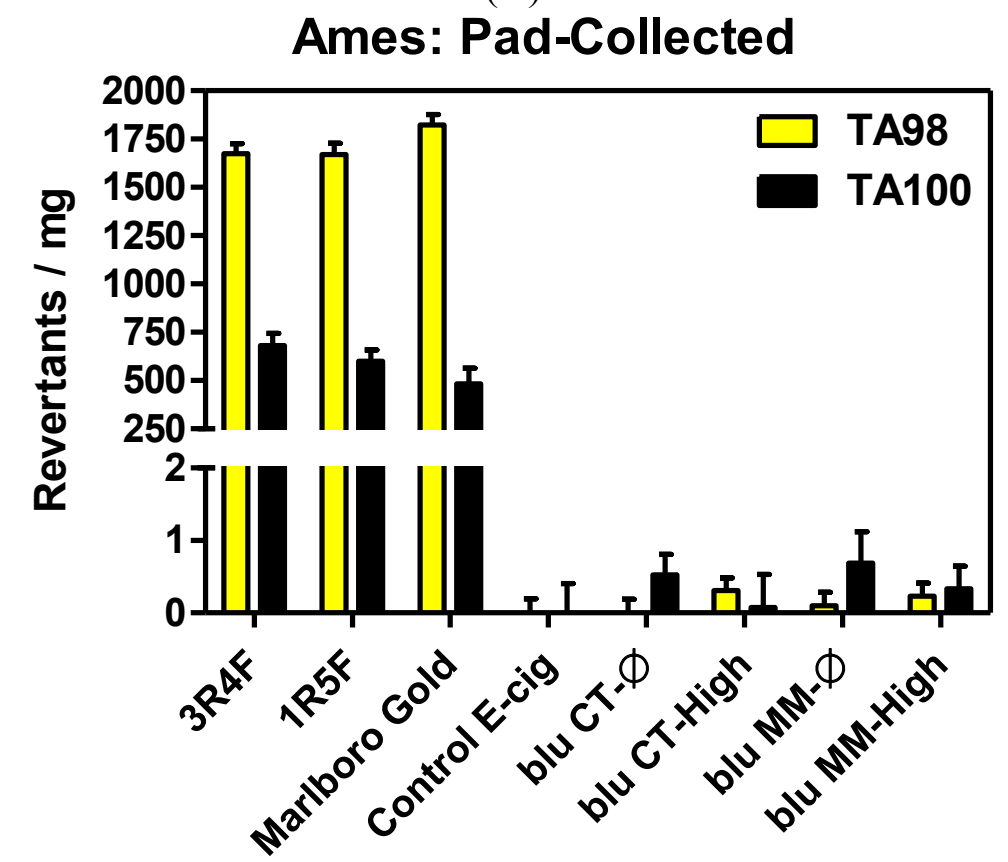

(B) 
Figure 3. Cont.

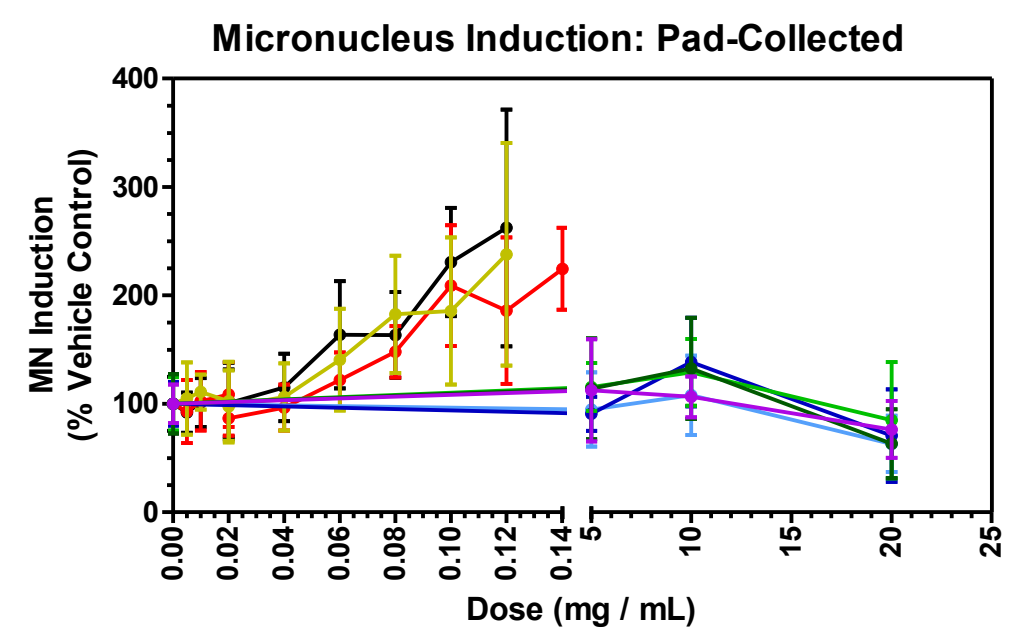

(C)

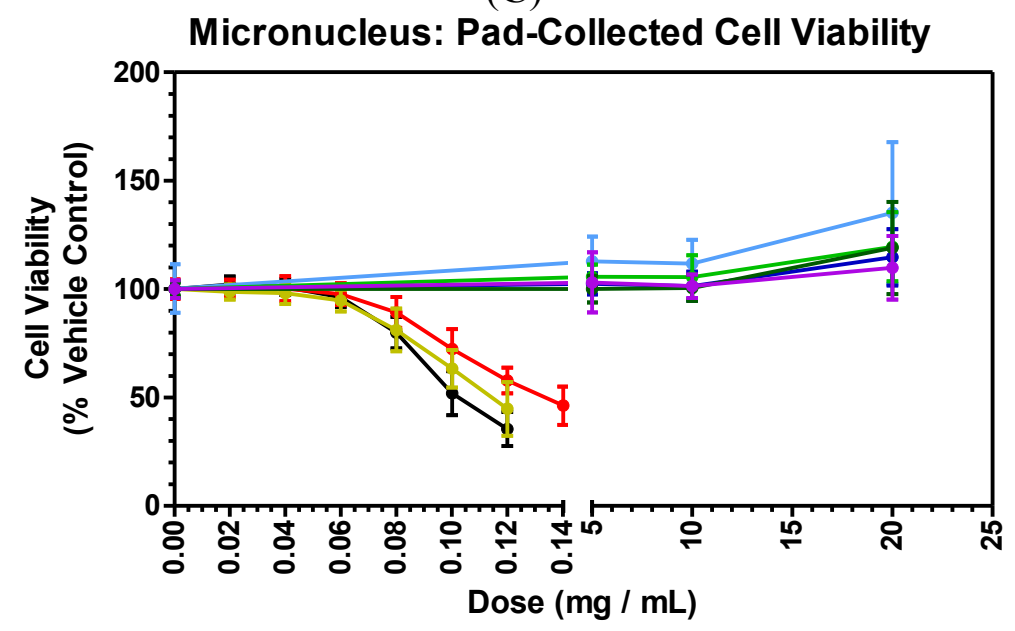

(D)

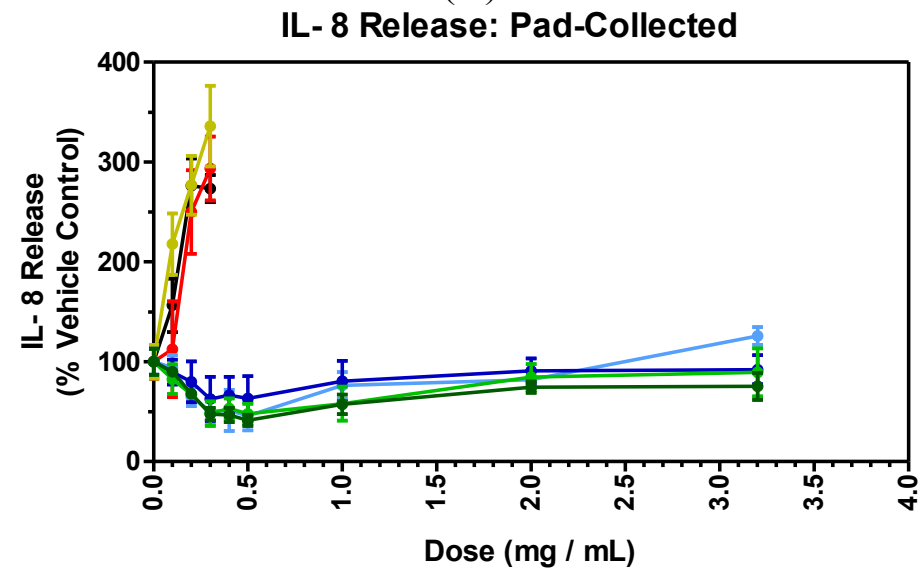

(E)

\subsection{E-Cigarettes and Conventional Cigarettes}

In order to study the comparative toxicities of the e-cig aerosols and tobacco smoke, all products were smoked by the standardized CI profile with the aerosols or smoke from each product being collected on a pad as described in the Experimental Section. The pad-collected tobacco smoke matter was extracted in DMSO because it has been widely applied as a vehicle for in vitro assays of test 
articles of limited water solubility due to its excellent solvent properties for both polar and non-polar compounds and its moderate toxicity to test organisms [32,33]. The reasoning for the concentration ranges utilized in this study was to limit the level of DMSO in order to avoid any solvent specific effects on the assays [32]. The toxicological responses of the pad-collected e-cig aerosols and cigarette smoke are shown in Figure 3A-E.

\subsection{E-Cigarettes and Conventional Cigarettes: Cytotoxicity}

The cytotoxicity of e-cig pad-collected aerosol is shown in Figure 3A. The e-cig pad-collected aerosol was not cytotoxic at all tested levels. For comparative purposes, different levels of WTPM from tobacco cigarettes were also tested. A dose-dependent increase in cell death was observed for 3R4F, 1R5F and Marlboro Gold cigarettes with up to $90 \%$ cell death at the $0.5 \mathrm{mg} / \mathrm{mL}$ maximum applied dose. The WTPM mediated cytotoxicity results are in agreement with previously reported studies $[12,34]$. It was not possible to quantify the comparative cytotoxicity in terms of traditional $\mathrm{EC}_{50}$ values (a dose which induces 50\% cell death) since no cell death was observed at any concentration used for all e-cig samples (Table 2 and Figure 3A).

There was an observed increase in cellular viability in cells treated with e-liquids (Figure 1A) and lower doses of pure nicotine (Figure 2A). Also treatment with e-cig aerosols resulted in a similar increase in cellular viability (Figure 3A). This observed increase in cellular viability for pure nicotine and both e-cig liquids and pad-collected aerosols could be related to nicotine's effect on cellular proliferation and protection [27].

Table 2. NRU EC 50 values for WTPM only (mean $\pm \mathrm{SE}$ ). $\mathrm{EC}_{50}$ expressed in $\mathrm{mg} / \mathrm{mL}$ to correct for differences in dose volumes between exposure methods. ${ }^{\dagger} \mathrm{ND}$ : e-cig pad-collected aerosols $\mathrm{EC}_{50}$ not determined since cytotoxicity was not detected at doses tested.

\begin{tabular}{ccc}
\hline \multicolumn{3}{c}{ Pad-Collected Matter: Smoke and Aerosols } \\
\hline Sample & NRU $^{\text {EC }} \mathbf{5 0}(\mathbf{m g} / \mathbf{m L})$ & S.E. \\
\hline 3R4F & 0.196 & 0.010 \\
1R5F & 0.237 & 0.014 \\
Marlboro Gold & 0.204 & 0.009 \\
Control e-cig & $\mathrm{ND}^{\dagger}$ & -- \\
blu CT-Ø & $\mathrm{ND}^{\dagger}$ & -- \\
blu CT-High & $\mathrm{ND}^{\dagger}$ & -- \\
blu MM- $\varnothing$ & $\mathrm{ND}^{\dagger}$ & -- \\
blu MM-High & $\mathrm{ND}^{\dagger}$ & -- \\
\hline
\end{tabular}

Similar findings were reported for aqueous extracts of aerosols from various commercial e-cigs studied in cultured mammalian fibroblast and myocardial cells $[9,10]$. Both studies also reported that some aqueous extracts of e-cig aerosols showed cytotoxicity related to flavors, but were significantly less cytotoxic than cigarette smoke extracts. This study evaluated two flavored e-cigs, with and without nicotine (Table 1).

With e-liquids and pad-collected aerosols, no nicotine or flavor specific cytotoxic effects were evident with e-cigs without nicotine, blu MM-Ø, and blu CT- $\varnothing$, and with nicotine as high as 
$24 \mathrm{mg} / \mathrm{mL}$, blu MM-High and blu CT-High (Figures 1A and 3A). The cytotoxicity and inflammatory response of L-nicotine in this cell culture system (Figure 2) was also tested. No cytotoxicity and inflammation (IL-8 release) were observed below $2.5 \mathrm{mg} / \mathrm{mL}$ and $1.0 \mathrm{mg} / \mathrm{mL}$ nicotine, respectively (Figure 2A,B). The highest level of nicotine in e-liquids tested was about $0.5 \mathrm{mg} / \mathrm{mL}$ (Table 1), which was below the concentrations of L-nicotine required to induce cytotoxicity and IL-8 release in this experimental method. In addition, the WTPM from tobacco cigarettes at $0.5 \mathrm{mg} / \mathrm{mL}$ was extremely cytotoxic (Figure 3A), corresponding to a nicotine concentration of approximately $0.04 \mathrm{mg} / \mathrm{mL}$, which was well below nicotine mediated toxic levels, demonstrating that WTPM induced cytotoxicity was not mediated by nicotine.

\subsection{E-Cigarettes and Conventional Cigarettes: Mutagenicity}

The mutagenicity of pad-collected smoke and aerosols of tobacco cigarettes and e-cigs, respectively, is shown in Figure 3B. No activity was observed for control e-cig samples in the Ames assay. The specific activity for all tobacco cigarettes was in the range of 1600-1850 and 500-750 revertants/mg WTPM for TA98 and TA100, respectively (Figure 3B). Historically, WTPM prepared under the same smoking conditions has been shown to have similar levels of specific activity (revertants/mg) [35].

No increase in Ames activity was observed for any e-cigs used in this study and the revertants/mg was extremely low and within assay background measurements $(<2$ revertants $/ \mathrm{mg})$. It was not possible to quantify the specific activities for e-cig aerosols since no increase in revertant counts was observed with increasing doses for all tested e-cig samples (Figure 3B).

\subsection{E-Cigarettes and Conventional Cigarettes: Genotoxicity}

The cell viability and clastogenic effects of WTPM and e-cig pad-collected aerosols are presented in Figure 3C,D. The pad-collected aerosol from the control e-cig containing glycerol/water and the solvent (DMSO) control did not induce any MN formation. A significant dose-dependent WTPM mediated induction in $\mathrm{MN}$ formation was observed with all tobacco cigarettes $(3 \mathrm{R} 4 \mathrm{~F}, 1 \mathrm{R} 5 \mathrm{~F}$ and Marlboro Gold). No increase in the MN formation was observed for pad-collected aerosols from e-cigs at all doses tested (Figure 3C). The maximum induction in the $\mathrm{MN}$ formation with tobacco cigarettes was about 2.5 to 3 -fold over background at about $0.12 \mathrm{mg} / \mathrm{mL}$ WTPM. A sharp decrease in the WTPM-induced MN formation was observed at dose levels higher than $0.12 \mathrm{mg} / \mathrm{mL}$ WTPM due to the decrease in cell viability (Figure 3D). Similar MN findings have been reported [31]. The dose at which tobacco cigarette WTPM induced maximum MN formation is approximately 166-fold lower than the maximum e-cig pad-collected aerosol dose $(20 \mathrm{mg} / \mathrm{mL})$ tested, which had no observed induced MN formation.

\subsection{E-Cigarettes and Conventional Cigarettes: Inflammation}

The inflammatory responses, as measured by IL- 8 release from cells treated with tobacco WTPM and e-cig aerosols are presented in Figure 3E. No IL-8 release was observed for control samples. The pad-collected aerosols from all e-cigs did not induce any IL-8 release at all doses tested (Figure 3E). In contrast, a WTPM mediated dose-dependent increase in IL-8 release was observed for all tobacco 
cigarettes. A sharp decrease in the IL-8 level at WTPM levels over $0.3 \mathrm{mg} / \mathrm{mL}$ was noticed (data not shown) since significant cytotoxicity was observed at those doses (Figure 3A).

The WTPM dose at which a significant IL- 8 release was observed $(0.15 \mathrm{mg} / \mathrm{mL})$ was about 20 -fold lower than the maximum e-cig pad-collected aerosol tested dose $(3.2 \mathrm{mg} / \mathrm{mL})$, at which no inflammatory effect was observed. The release of IL-8 in cultured cells by different cigarette smoke preparations has been reported [36] and this inflammatory response has been associated with oxidative stress due to the free radicals present in cigarette smoke [37].

At the lower doses of e-cig pad-collected aerosols utilized in this study, compared to the control, a lower release of IL-8 was observed (Figure 3E). That effect was also evident in cells treated with lower doses of pure nicotine (Figure 2B). This phenomenon of a lower release of an inflammatory cytokine (IL-8) is associated with the anti-inflammatory effects of nicotine [38]. There may be an association between the lower nicotine present in e-cig pad-collected aerosols and anti-inflammatory effects.

\subsection{Nicotine Equivalence}

Assessment of in vitro responses observed in this study was also calculated based on the level of nicotine present in the test samples. The level of nicotine concentrations measured in the prepared samples are shown in Table 1 but varied depending on sample volume and toxicity endpoint measured in this study. The upper limit of nicotine measured in tobacco cigarette WTPM was about $0.025 \mathrm{mg} / \mathrm{mL}$, e-cig pad-collected aerosol was about $0.223 \mathrm{mg} / \mathrm{mL}$ and e-liquid was about $0.522 \mathrm{mg} / \mathrm{mL}$. Thus, the nicotine concentration was about 10 to 20 -fold higher in e-cig samples as compared to conventional cigarette samples. No nicotine mediated cellular toxicity was observed at $2.5 \mathrm{mg}$ nicotine $/ \mathrm{mL}$ (Figure 2A). At low doses up to $2.0 \mathrm{mg} / \mathrm{mL}$, L-nicotine in fact increased the cellular proliferation as indicated by the higher cell viability than the control (Figure 2A) indicating a cellular protective response [27] as well as lower release of IL-8 in the media than control (Figure 2B) suggesting the anti-inflammatory properties of nicotine [38].

The average human exposure to nicotine on a 10-puff basis from a typical tobacco cigarette (tar $11.4 \pm 0.1 \mathrm{mg} / \mathrm{cig}$ ) is about $2.0 \mathrm{mg}$ and from an e-cig product (labeled $24 \mathrm{mg}$ nicotine) is about $0.23 \mathrm{mg}$ under the similar CI smoking profile used for this study [39]. Therefore, it was evident that the nicotine levels in e-cig treatments were well below the toxic level of L-nicotine and represent comparative nicotine levels present in the tested e-cig and conventional cigarette samples. In addition, based on literature on the beneficial role of nicotine, relative to e-liquids and pad-collected aerosols used in this study and pure nicotine effects, there may be an association between lower levels of nicotine present in samples used in this study and cellular protection as well as anti-inflammatory effects [27,38].

Under the experimental conditions used to evaluate traditional tobacco burning cigarettes, e-cigs did not produce any meaningful toxic effects as measured by four in vitro endpoints. These results demonstrate the potential for e-cigs to significantly reduce the toxicological impact when compared to traditional tobacco burning cigarettes. 


\subsection{Comparable Human Exposure: Conventional and E-Cig}

The comparative human exposure to tobacco cigarette smoke and e-cig aerosol is important in order to assess e-cig mediated reduced exposure and reduced harm. It has been reported that a smoker with one pack-a-day tobacco cigarette consumption inhales on average about $261 \mathrm{mg} / \mathrm{m}^{3}$ cigarette tar [40], equivalent to about $271 \mu \mathrm{g} / \mathrm{mL}$ or $0.271 \mathrm{mg} / \mathrm{mL}$ [40]. Internal study indicated the range of e-cig aerosol delivery to be in the range of $0.5-1.5 \mathrm{mg} /$ puff under Canadian Intense conditions (39). Assuming similar e-cig use as a conventional tobacco cigarette (200 puffs), the upper limit of human exposure to e-cig aerosol is approximately $300 \mathrm{mg}$ or approximately $250 \mu \mathrm{g} / \mathrm{mL}$ or $0.25 \mathrm{mg} / \mathrm{mL}$. The range of e-cig pad-collected aerosol used in the present study was $3.2-20 \mathrm{mg} / \mathrm{mL}$. No adverse toxicological events were observed in this study even when the e-cig aerosol levels used were about 12-78 times higher than expected with normal e-cig use.

\subsection{Contribution of Findings to Tobacco Harm Reduction and E-Cigs}

The concept of Tobacco Harm Reduction (THR) has been advanced as a pragmatic approach to achieving reductions in the adverse public health impacts of cigarette smoking in the near term; in parallel with social, educational, and regulatory strategies intended to reduce and discourage cigarette smoking, particularly among adolescents [4,41-43].

The use of non-combustible SLT products such as Swedish-style snus and traditional moist snuff are demonstrably on the order of $98 \%$ less harmful in terms of risks for lung cancer, COPD, CVD, and other cancers, (including oral cancers) as compared to cigarette smoking [11,41,44,45].

Similarly, NRT products such as dermal patches and chewing gums have been shown to be safe and efficacious in clinically-managed and over-the-counter consumer usage. Therapeutic nicotine vapor inhaler devices and aerosol sprays for nasal and oral use have to date demonstrated similar benefits and low risks in facilitating smoking cessation [46]. The efficacy of such conventional NRT cessation aids has, however, proven in practice to fall short ( $7 \%$ cessation success) of what is needed by a considerable number of smokers [47]. These smokers consistently report that taste, sensory and behavioral components experienced in the act of cigarette smoking are substantial motivators of the smoking behavior and may well comprise a population that could achieve substantially higher success in quitting through use of products that mimic the behavior element of smoking as well as the delivery of nicotine. Therefore, the use of e-cigs that provide some of the taste, sensory and behavioral components of conventional tobacco cigarette smoking may hold substantial promise in defining the potential benefits of the THR paradigm [48].

Despite the absence of long-term epidemiologic data on any chronic disease risk, a growing body of recent literature is consistent with an expectation that the use of e-cigs is unlikely to raise serious health concerns [49,50], particularly in comparison to those that result from the smoking of conventional cigarettes [7]. This conclusion is currently based, and further supported by this study and on a growing number of independent analyses of commercially-available e-cig liquids and product aerosols from markets around the world, that have consistently reported very low or undetectable levels of most tobacco smoke constituents that are known or suspected to play a prominent role in the etiology of serious tobacco-related diseases. [7,51-59]. 
There are various essential and contributory components to the THR framework, including product use and behavior, taste, nicotine delivery, product chemistry, toxicity and clinical safety. This study shows that neither the e-cig liquids nor collected aerosols produced any meaningful toxic effects in widely used in vitro test systems. These findings add additional value to the increasing body of scientific weight-of-evidence supporting the potential inclusion of e-cigs into THR paradigm.

\section{Conclusions}

In summary, this comparative in vitro toxicity study of e-cigs, SLT, NRT and tobacco cigarette products demonstrates the following:

(1) E-cigs vs. Tobacco WTPM: At doses up to approximately 100-fold higher than typical cigarette smoke exposures, blu e-cig liquids and pad-collected aerosols had no-to-extremely low in vitro activity (NRU, Ames, MN and IL-8) when compared to WTPM from tobacco burning cigarettes. WTPM activity was up to approximately 6,000 times higher than e-cigs.

(2) E-cigs vs. SLT and NRT: blu e-cig liquids demonstrated similar no-to-extremely low in vitro activity as aqueous extracts from a commercial nicotine lozenge (NRT) and commercial SLT products (snus and snuff).

(3) Effect of Nicotine: In vitro activities (NRU, Ames, MN and IL-8) measured for blu e-cig exposures, with and without nicotine, were similar for all sample types, indicating that the presence of nicotine, at the levels tested, did not contribute to any toxicological effects, confirmed by the lack of cytotoxicity and inflammation response of L-nicotine at comparative levels.

(4) Effect of Flavors: In vitro activities (NRU, Ames and $\mathrm{MN}$ ) for the commercial blu e-cigs were indistinguishable from control (glycerol/water); indicating these flavors (CT and $\mathrm{MM}$ ), at the levels tested, had no detectable impact on the cytotoxicity and genotoxicity endpoints utilized in this study. There was some observed IL-8 induction for some e-liquids, albeit at the highest doses tested.

(5) Liquid vs. Pad-Collected Aerosol: In vitro results for blu e-cigs, in this study, were similar for the different exposure methods (e-liquids and pad-collected aerosol); demonstrating no detectable impact on the in vitro toxicological responses when the e-liquids were aerosolized.

(6) SLT vs. Tobacco WTPM: SLT extracts added to the test systems at levels up to 54-fold higher than those used for Tobacco-WTPM generated by burning cigarettes was markedly less cytotoxic and mutagenic, and evoked a significantly lower IL- 8 response at all dose levels evaluated. The effects of the SLT extracts in the assays were statistically indistinguishable from those of the e-cig and NRT preparations.

With respect to the study, lack of any meaningful in vitro acute toxicity for blu e-cigs and extremely low levels of chemical constituents measured in blu [39] and the analysis of known reduced risk products such as NRT and SLT has the potential to demonstrate a decreased human health impact as compared to conventional tobacco-burning cigarettes. 


\section{Acknowledgments}

The authors would like to thank Edward Robinson, Dan J. Heck, Sherwin Yan and Carl D'Ruiz for critical review of the manuscript and Mark Sackfield for technical assistance in sample preparation for toxicological testing.

\section{Author Contributions}

Manoj Misra: Participated in study design and execution of the study, conducted cytotoxicity (NRU) and IL-8 release measurements (e-liquids and pad-collected matter from e-cigs and tobacco cigarettes, aqueous extracts of SLTs and NRT) and related data collection and interpretation, and constructed manuscript as principal writer.

Robert D. Leverette: Participated in study design and execution of the study, coordinated sample preparation (e-liquids, pad-collected aerosols and smoke condensates, SLT and NRT aqueous extracts), conducted mutagenesis Ames test measurements (e-liquids and pad-collected matter from e-cigs and tobacco cigarettes, aqueous extracts of SLTs and NRT) and related data collection, compilation and interpretation and presentation of data (graphs and tables).

Bethany T. Cooper: Conducted MN formation measurements (e-liquids and pad-collected matter from e-cigs and tobacco cigarettes, aqueous extracts of SLTs and NRT) and related data collection.

Melanee B. Bennett: Maintained and provided cultured cells, A549 and CHO cells, for the study and assisted in conducting cytotoxicity (NRU) measurements (e-liquids and pad-collected matter from e-cigs and tobacco cigarettes, aqueous extracts of SLTs and NRT).

Steven E. Brown: Participated in study design and critical review of the manuscript.

\section{Conflicts of Interest}

The authors are Lorillard Tobacco Company employees and declare no conflict of interest with respect to the research, authorship, and/or publication of this article.

\section{References}

1. Ayers, J.W.; Ribisl, K.M.; Brownstein, J.S. Tracking the rise in popularity of electronic nicotine delivery systems (electronic cigarettes) using search query surveillance. Am. J. Prev. Med. 2011, 40, 448-453.

2. Etter, J.-F.; Bullen, C.; Flouris, A.D.; Laugesen, M.; Eissenberg, T. Electronic nicotine delivery systems: A research agenda. Tob. Control. 2011, 20, 243-248.

3. Levitz, J.S.; Bradley, T.P.; Golden, A.L. Overview of smoking and all cancers. Med. Clin. North Am. 2004, 88, 1655-1675.

4. Polosa, R.; Rodu, B.; Caponnetto, P.; Maglia, M.; Raciti, C. A fresh look at tobacco harm reduction: The case for the electronic cigarette. Harm Reduct. J. 2013, 10, doi:10.1186/1477-7517-10-19.

5. Brown, B.; Beard, E.; Kotz, D.; Michie, S.; West, R. Real-world effectiveness of e-cigarettes when used to aid smoking cessation: A cross-sectional population study. 2014, 109, 1531-1540.

6. Statement from Specialists in Nicotine Science and Public Health Policy. Available online: http://www.nicotinepolicy.net/documents/letters/MargaretChan.pdf (accessed on 27 October 2014). 
7. Goniewicz, M.L.; Knysak, J.; Gawron, M.; Kosmider, L.; Sobczak, A.; Kurek, J.; Prokopowicz, A.; Jablonska-Czapla, M.; Rosik-Dulewska, C.; Havel, C.; et al. Levels of selected carcinogens and toxicants in vapour from electronic cigarettes. Tob. Control 2013, 23, 1-7.

8. Farsalinos, K.E.; Polosa, R. Safety evaluation and risk assessment of electronic cigarettes as tobacco cigarette substitutes: A systematic review. Ther. Adv. Drug Safety 2014, 5, 67-86.

9. Romagna, G.; Allifranchini, E.; Bocchietto, E.; Todeschi, S.; Esposito, M.; Farsalinos, K.E. Cytotoxicity evaluation of electronic cigarette vapor extract on cultured mammalian fibroblasts (clearstream-life): Comparison with tobacco cigarette smoke extract. Inhal. Toxicol. 2013, 25, 354-361.

10. Farsalinos, K.E.; Romagna, G.; Allifranchini, E.; Ripamonti, E.; Bocchietto, E.; Todeschi, S.; Tsiapras, D.; Kyrzopoulos, S.; Voudris, V. Comparison of the cytotoxic potential of cigarette smoke and electronic cigarette vapour extract on cultured myocardial cells. Int. J. Environ. Res. Public Health 2013, 10, 5146-5162.

11. Nutt, D.J.; Phillips, L.D.; Balfour, D.; Curran, V.; Dockrell, M.; Foulds, J.; Fagerstrom, K.; Letlape, K.; Milton, A.; Polosa, R.; et al. Estimating the harms of nicotine-containing products using the MCDA approach. Eur. Addict. Res. 2014, 20, 218-225.

12. Arimilli, S.; Damratoski, B.E.; Bombick, B.; Borgerding, M.F.; Prasad, G.L. Evaluation of cytotoxicity of different tobacco product preparations. Regul. Toxicol. Pharmacol. 2012, 64, 350-360.

13. CORESTA In Vitro Toxicology Task Force. The Rationale and Strategy for Conducting In Vitro Toxicology Testing of Tobacco Smoke. Available online: http://www.coresta.org/Reports/IVT_ TF_Rationale-IVT-Testing-Tob.-Smoke_Report_Jun04.pdf (accessed on 27 October 2014).

14. Determination of "Tar," Nicotine and Carbon Monoxide in Mainstream Tobacco Smoke-Official Method. Available online: http://laws.justice.gc.ca/en/T-11.5/SOR-2000-272/182471.html. (accessed on 8 January 2006).

15. Rickert, W.S.; Wright, W.G.; Trivedi, A.H.; Momin, R.A.; Lauterbach, J.H. A comparative study of the mutagenicity of various types of tobacco products. Regul. Toxicol. Pharmacol. 2007, 48, $320-330$.

16. Official Method T-115. Determination of "Tar", Nicotine and Carbon Monoxide in Mainstream Tobacco Smoke. Available online: http://laws-lois.justice.gc.ca/eng/regulations/SOR-2000-273/ page-14.html (accessed on 29 October 2014).

17. Borenfreund, E.; Puerner, J.A. Toxicity determined in vitro by morphological alterations and neutral red absorption. Toxicol. Letters 1985, 24, 119-124.

18. Bombick, D.W.; Doolittle, D.J. The role of chemical structure and cell type in the cytotoxicity of low molecular weight aldehydes and pyridines. In Vitro Toxicol. 1995, 8, 349-356.

19. Human IL-8 ELISA Kit. For the Quantitative Determination of Human IL- 8 Concentrations in Serum, Plasma, Cell Culture Supernatant and Other Biological Fluids. Available online: http://www.abazyme.com/inserts/EL10008.pdf (accessed on 20 October 2014).

20. Aufderheide, M.; Gressmann, H. A modified ames assay reveals the mutagenicity of native cigarette mainstream smoke and its gas vapour phase. Exp. Toxicol. Pathol. 2007, 58, 383-392.

21. Maron, D.M.; Ames, B.N. Revised methods for the salmonella mutagenicity test. Mutat. Res. 1983, 113, 173-215. 
22. Diaz, D.; Scott, A.; Carmichael, P.; Shi, W.; Costales, C. Evaluation of an automated in vitro micronucleus assay in CHO-K1 cells. Mutat. Res. 2007, 630, 1-13.

23. Kirkland, D.; Reeve, L.; Gatehouse, D.; Vanparys, P. A core in vitro genotoxicity battery comprising the AMES test plus the in vitro micronucleus test is sufficient to detect rodent carcinogens and in vivo genotoxins. Mutat. Res. 2011, 721, 27-73.

24. Aggarwal, B.B.; Shishodia, S.; Sandur, S.K.; Pandey, M.K.; Sethi, G. Inflammation and cancer: How hot is the link? Biochem. Pharmacol. 2006, 72, 1605-1621.

25. Balkwill, F.; Charles, K.A.; Mantovani, A. Smoldering and polarized inflammation in the initiation and promotion of malignant disease. Cancer Cell 2005, 7, 211-217.

26. Bahl, V.; Lin, S.; Xu, N.; Davis, B.; Wang, Y.H.; Talbot, P. Comparison of electronic cigarette refill fluid cytotoxicity using embryonic and adult models. Reprod. Toxicol. 2012, 34, 529-537.

27. Balharry, D.; Sexton, K.; BeruBe, K.A. An in vitro approach to assess the toxicity of inhaled tobacco smoke components: Nicotine, cadmium, formaldehyde and urethane. Toxicology 2008 , 244, 66-76.

28. Scott, K.; Saul, J.; Crooks, I.; Camacho, O.M.; Dillon, D.; Meredith, C. The resolving power of in vitro genotoxicity assays for cigarette smoke particulate matter. Toxicol. in Vitro 2013, 27, 1312-1319.

29. Rosefort, C.; Fauth, E.; Zank1, H. Micronuclei induced by aneugens and clastogens in mononucleate and binucleate cells using cytokinesis block assay. Mutagenesis 2004, 19, 277-284.

30. Fuke, S.; Betsuyaku, T.; Nasuhara, Y.; Morikawa, T.; Katoh, H.; Nishimura, M. Chemokines in bronchiolar epithelium in the development of chronic obstructive pulmonary disease. Am. J. Respir. Cell Mol. Biol. 2004, 31, 405-412.

31. Moretto, N.; Facchinetti, F.; Southworth, T.; Civelli, M.; Singh, D.; Patacchini, R. $\alpha, \beta$-Unsaturated aldehydes contained in cigarette smoke elicit IL-8 release in pulmonary cells through mitogen-activated protein kinases. Am. J. Physiol. Lung Cell Mol. Physiol. 2009, 296, L839-L848.

32. Baker, R.R.; Massey, E.D.; Smith, G. An overview of the effects of tobacco ingredients on smoke chemistry and toxicity. Food Chem. Toxicol. 2004, 42, S53-S83.

33. Misra, M.; Leverette, R.D.; Hamm, J.T.; Vulimiri, S.V. In vitro toxicological evaluation of cigarette smoke particulate matter: Effect of Dimethyl Sulfoxide (DMSO) as solvent. Beiträge zur Tabakforschung International 2010, 24, 2-9.

34. Jianhua, Y.; Gao, Q.; Mi, Q.; Li, X.; Miao, M.; Cheng, P.; Luo, Y. In vitro micronucleus assay for the analysis of total particulate matter in cigarette smoke: Comparison of flow cytometry and laser scanning cytometry with microscopy. Mutat. Res. 2013, 755, 120-125.

35. Rickert, W.S.; Trivedi, A.H.; Momin, R.A.; Wright, W.G.; Lauterbach, J.H. Effect of smoking conditions and methods of collection on the mutagenicity and cytotoxicity of cigarette mainstream smoke. Toxicol. Sci. 2007, 96, 285-293.

36. Fields, W.R.; Leonard, R.M.; Odom, P.S.; Nordskog, B.K.; Ogden, M.W.; Doolittle, D.J. Gene expression in Normal Human Bronchial Epithelial (NHBE) cells following in vitro exposure to cigarette smoke condensate. Toxicol. Sci. 2005, 86, 84-91.

37. Pryor, W.A.; Stone, K. Oxidants in cigarette smoke. Radicals, hydrogen peroxide, peroxynitrate, and peroxynitrite. Ann. N. Y. Acad. Sci. 1993, 686, 12-28. 
38. Kalra, R.; Singh, S.P.; Pena-Philippides, J.C.; Langley, R.J.; Razani-Boroujerdi, S.; Sopori, M.L. Immunosuppressive and anti-inflammatory effects of nicotine administered by patch in an animal model. Clin. Vaccine Immunol. 2004, 11, 563-568.

39. Tayyarah, R.; Long, G.A. Comparison of select analytes in aerosol from e-cigarettes with smoke from conventional cigarettes and with ambient air. Reg. Toxicol. Pharmacol. 2014, 2014, doi:10.1016/j.yrtph.2014.10.010.

40. Finch, G.L.; Nikula, K.J.; Chen, B.T.; Barr, E.B.; Chang, I.Y.; Hobbs, C.H. Effect of chronic cigarette smoke exposure on lung clearance of tracer particles inhaled by rats. Fundam. Appl. Toxicol. 1995, 24, 76-85.

41. Rodu, B. The scientific foundation for tobacco harm reduction, 2006-2011. Harm Reduct. J. 2011, 8, doi:10.1186/1477-7517-8-19.

42. McNeill, A.; Munafò, M.R. Reducing harm from tobacco use. J. Psychopharmacol. 2012, 2012, doi:10.1177/0269881112458731.

43. Fagerström, K.O.; Bridgmanb, K. Tobacco harm reduction: The need for new products that can compete with cigarettes. Addict. Behav. 2014, 39, 507-511.

44. Gartner, C.E.; Hall, W.D. Should Australia lift its ban on low nitrosamine 576 smokeless tobacco products? Med. J. Aust. 2008, 188, 44-46.

45. Phillips, C.V.; Rodu, B. Tobacco harm reduction: Opportunity and opposition. Drugs Alcohol Today 2013, 13, 73-78.

46. The Use of Nicotine Replacement Therapy to Reduce Harm in Smokers. Available online: htpp://mhra.gsi.gov.uk (accessed on 27 October 2014).

47. Moore, D.; Aveyard, P.; Connock, M.; Wang, D.; Fry-Smith, A.; Barton, P. Effectiveness and safety of nicotine replacement therapy assisted reduction to stop smoking: Systematic review and meta-analysis. BMJ 2009, 338, doi:10.1136/bmj.b1024.

48. Farsalinos, K.E.; Romagna, G.; Tsiapras, D.; Kyrzopoulos, S.; Spyrou, A.; Voudris, V. Impact of flavour variability on electronic cigarette use experience: An internet survey. Int. J. Environ. Res. Public Health 2013, 10, 7272-7282.

49. Farsalinos, K.E.; Romagna, G.; Tsiapras, D.; Kyrzopoulos, S.; Voudris, V. Characteristics, perceived side effects and benefits of electronic cigarette use: A worldwide survey of more than 19,000 consumers. Int. J. Environ. Res. Public Health 2014, 11, 4356-4373.

50. Hajek, P.; Etter, J.-F.; Benowitz, B.; Eissenberg, T.; McRobbie, H. Electronic cigarettes: Review of use, content, safety, effects on smokers and potential for harm and benefit. Addiction 2014, 2014, doi:10.1111/add.12659.

51. Ruyan ${ }^{\circledR}$ E-cigarette Bench-Top Tests. Available online: http://www.healthnz.co.nz/DublinEcigBench topHandout.pdf (accessed 20 November 2013).

52. Evaluation of e-Cigarettes. Available online: http://www.fda.gov/downloads/drugs/Scienceresearch/ UCM173250.pdf (accessed on 10 November 2013).

53. Hadwiger, M.; Trehy, M.; Ye, W.; Moore, T.; Allgire, J.; Westenberger, B. Identification of amino-tadalafil and rimonabant in electronic cigarette products using high pressure liquid chromatography with diode array and tandem mass spectrometric detection. J. Chromatogr. A. 2010, $1217,7547-7555$. 
54. Cahn, Z.; Siegel, M. Electronic cigarettes as a harm reduction strategy for tobacco control: A step forward or a repeat of past mistakes? J. Public Health Policy 2011, 32, 16-31.

55. Pellegrino, R.M.; Tinghino, B.; Mangiaracina, G.; Marani, A.; Vitali, M.; Protano, C.; Osborn, J.F.; Cattaruzza, M.S. Electronic cigarettes: An evaluation of exposure to chemicals and fine Particulate Matter (PM). Ann. Ig. 2012, 24, 279-288.

56. Kim, H.; Shin, H. Determination of tobacco-specific nitrosamines in replacement liquids of electronic cigarettes by liquid chromatography-tandem mass spectrometry. J. Chromatogr. A. 2013, 1291, 48-55.

57. Etter, J.; Zäther, E.; Svensson, S. Analysis of refill liquids for electronic cigarettes. Addiction 2013, 108, 1671-1679.

58. Williams, M.; Villarreal, A.; Bozhilov, K.; Lin, S.; Talbot, P. Metal and silicate particles including nanoparticles are present in electronic cigarette cartomizer fluid and aerosol. PLoS One 2013, 8, doi:10.1371/journal.pone.0057987.

59. Burstyn, I. Peering through the mist: Systematic review of what the chemistry of contaminants in electronic cigarettes tells us about health risks. BMC Public Health 2014, 14, doi:10.1186/ 1471-2458-14-18.

(C) 2014 by the authors; licensee MDPI, Basel, Switzerland. This article is an open access article distributed under the terms and conditions of the Creative Commons Attribution license (http://creativecommons.org/licenses/by/4.0/). 